\title{
ÉTICA DISCURSIVA Y LEGITIMIDAD DEL DERECHO
}

\section{La legitimidad normativa del Derecho}

obre la base de la ética discursiva, el problema del vínculo necesario entre Derecho y moral puede abordarse tanto desde el punto de vista de la moral como desde el punto de vista del Derecho. Esta es la razón por la que Jürgen Habermas ha tratado de responder tanto a la cuestión de por qué la moral necesariamente presupone el derecho como a la de por qué el Derecho necesariamente presupone la moral.

La moral procedimental presenta dos deficiencias que el Derecho puede contribuir a remediar. Una de estas deficiencias es el llamado problema de la imputación. En los discursos morales, la validez de las normas morales se evalúa bajo la premisa de que todos los concernidos deben seguir normas válidas. Por tanto, las normas válidas sólo pueden imputarse a alguien que pueda estar seguro de que cualquier otro también debe seguirlas. Sin embargo, la moral por sí sola no puede garantizar la seguridad de que todos seguirán sus normas. Esta deficiencia puede superarse transformando las normas morales válidas en normas jurídicamente obligatorias (Habermas, 1987, 13-14).

El otro defecto puede denominarse problema de la institucionalización. El discurso práctico-moral ideal está basado sobre ciertos presupuestos contrafácticos que nunca pueden darse por completo en la realidad. Los discursos reales inevitablemente están sometidos a restricciones temporales, espaciales y sociales. En orden a permitir la solución discursiva de problemas prácticos, los discursos deben institucionalizarse mediante reglas fijas: mediante reglas que regulen el principio y el fin de los discursos, los participantes en los mismos, los pasos argumentativos, el procedimiento de toma de decisiones, etc. La institucionalización requerida por los discursos reales no puede alcanzarse únicamente a través de normas morales; también en este aspecto el Derecho puede acudir en ayuda de la moral (Habermas, 1981a, 324-325; Habermas, 1987, 14-15). 
La interpretación que hace Habermas del Derecho como un remedio para los defectos de la moral procedimental puede verse como una justificación Moral del Derecho. Sin embargo, esta propuesta para la justificación del Derecho no sigue el programa de la teoría reconstructiva del que, según Habermas (1983, 107 ss.), la ética discursiva participa. Lo que Habermas trata de demostrar es más bien una necesidad sociológico-funcional. Es concebible que también la indispensabilidad de la moral para el Derecho pueda demostrarse en un nivel sociológico-funcional, por ejemplo, de la siguiente manera: el funcionamiento de un ordenamiento jurídico, su eficacia, requiere su legitimidad empírica, su aceptación, y esto, a su vez, requiere una cierta correspondencia sustancial del Derecho con las normas morales y las concepciones predominantes en la sociedad. Sin embargo, la tesis de la vinculación necesaria entre Derecho y moral formulada sobre la base de la ética discursiva es más ambiciosa: el Derecho está llamado a relacionarse necesariamente con la moral por medio de un vínculo que puede demostrarse en el nivel de la reconstrucción racional. Y este nivel, a su vez, implica un concepto normativo de legitimidad en lugar del concepto empírico utilizado en el nivel sociológico-funcional.

En un artículo reciente ${ }^{1}$, Robert Alexy ha mantenido que el Derecho implica conceptualmente la pretensión de corrección y que es precisamente esta pretensión la que establece un vínculo conceptual necesario entre Derecho y moral: las normas y los juicios jurídicos presentan una pretensión de validez análoga a las normas y juicios morales, la pretensión de corrección normativa. Desde el punto de vista de Alexy, esto puede mostrarse adoptando la perspectiva interna del que participa en el sistema jurídico y examinando el sistema jurídico principalmente como un sistema de procedimientos, esto es, no sólo como un sistema de normas. Desde esta perspectiva, uno puede comprobar que todo acto jurídico, no importa que se trate de actos legislativos o jurisdiccionales, incluye una pretensión de corrección normativa. Las pretensiones de corrección, a su vez, remiten a su toma en consideración en discursos que pueden considerarse como casos especiales de los discursos práctico-morales.

Según la teoría jurídica ético-discursiva, sólo aquellas normas y juicios jurídicos que pueden satisfacer las pretensiones de corrección, esto es, que pueden ser aceptados en los discursos práctico-morales pueden considerarse legítimos en el sentido

${ }^{1}$ Ratio Juris, vol. 2, 1989. 
normativo del término. Así, en la teoría jurídica el principio de la ética discursiva ${ }^{2}$ se aplica como criterio de legitimidad de las normas y juicios jurídicos. La distinción entre aceptación social de facto (Geltung) y validez (Gültigkeit) de las normas (Habermas, 1983, 69 ss.) se transfiere también a la teoría jurídica: la aceptación social de facto (legitimidad empírica) de las normas jurídicas no nos permite sacar conclusiones definitivas acerca de su validez, esto es, acerca de su legitimidad normativa.

La tesis de Alexy del vínculo conceptual necesario entre Derecho y moral no se circunscribe a un determinado tipo histórico de Derecho. Sin embargo, es evidente que la teoría jurídica ético-discursiva ha formulado, al menos implícitamente, su tesis central con referencia a un tipo histórico particular de Derecho, a saber el Derecho moderno occidental. Hasta que no entra en escena el Derecho moderno, el Derecho no puede ser examinado como un sistema de procedimientos en la forma que propone la tesis de Alexy. Con el Derecho moderno se alcanza, por primera vez, un sistema de procedimientos jurídicos diferenciados y especializados: procedimientos legalmente regulados para la creación de normas jurídicas y para la aplicación del Derecho. Estos procedimientos se complementan con la investigación dogmático-jurídica, que está especializada en la interpretación y la sistematización de las normas jurídicas. Con esta especificación del enfoque de la teoría jurídica ético-discursiva tocamos una cuestión central, cual es la de la vocación de universalidad de la teoría de la ética discursiva misma. Un elemento recurrente en la crítica dirigida a la ética discursiva es la acusación de etnocentrismo. Sin embargo, en este contexto me ocuparé de la teoría jurídica ético-discursiva como una teoría del Derecho moderno y dejaré a un lado el problema del etnocentrismo.

La ética discursiva es una ética procedimental que trata de formular, en lugar de principios sustantivos, reglas procedimentales para la solución de las cuestiones morales problemáticas. Correspondientemente, la ética discursiva aborda también las relaciones entre Derecho y moral desde un punto de vista procedimental. Desde la perspectiva de la ética discursiva, lo que se toma en cuenta no son primariamente las semejanzas y diferencias sustanciales entre las normas jurídicas y las morales, sino la relación entre los procedimientos jurídicos y los procedimientos

\footnotetext{
${ }^{2}$ Habermas $(1983,103)$ ha formulado este principio de la forma siguiente: Sólo pueden ser válidas las normas que aceptan o pueden aceptar todos los concernidos -esto es, todos los afectados por la norma en cuestión- como participantes en un discurso práctico.
} 
que la teoría de la ética discursiva ha diseñado para la solución de las cuestiones morales problemáticas. La teoría jurídica ético-discursiva no se limita a sostener simplemente que las normas y los juicios jurídicos reclaman una pretensión de validez análoga a la de las normas y juicios morales. Mantiene también que los procedimientos jurídicos del Derecho moderno pueden caracterizarse como discursos práctico-morales institucionalizados. Esto significa que el propio Derecho moderno ha adoptado, institucionalizado, el criterio de legitimidad formulado sobre la base de la ética discursiva; el concepto de legitimidad normativa no es, pues, un patrón externo al Derecho moderno, sino un requisito interno que abre la posibilidad de la llamada crítica inmanente del Derecho.

Para la justificación de la última tesis hay dos alternativas ambas conformes con el programa de la reconstrucción racional. Primera, la reconstrucción puede centrarse sobre las normas jurídicas que regulan los procedimientos jurídicos, tales como los procedimientos para la creación de normas jurídicas y para la aplicación del Derecho. La tesis puede considerarse confirmada si puede mostrarse que estas normas implican la solución de problemas jurídicos en un procedimiento discursivo análogo al de los discursos práctico-morales. Y segunda, la reconstrucción puede centrarse sobre la acción de los agentes que participan en los procedimientos jurídicos, sobre las presuposiciones implícitas de su acción. Esta es la alternativa sobre la que Alexy ha basado su argumentación sobre el vínculo conceptual necesario entre Derecho y moral. Sin embargo, cuando uno trata de demostrar la discursividad de los procedimientos jurídicos a través de una reconstrucción de este tipo, se plantea el siguiente problema: ¿está permitido llegar a conclusiones sobre los procesos por medio de los cuales las normas y juicios jurídicos han sido producidos desde las pretensiones de validez de estas normas y juicios? Sobre este problema volveré más adelante, cuando examine el problema de la naturaleza discursiva de la aplicación del Derecho. Antes de ello, comentaré la interpretación que hace Habermas de los procedimientos para la creación de normas jurídicas como discursos morales institucionalizados para la justificación de normas.

\section{Los procedimientos de creación de normas jurídicas}

La tesis de Habermas consiste en que las constituciones de las democracias occidentales, con sus disposiciones sobre la soberanía popular, sobre el Parlamento y su procedimiento legislativo, 
así como sobre tos derechos políticos fundamentales, han institucionalizado jurídicamente el discurso práctico como un procedimiento para producir nuevas normas jurídicas o, más exactamente, para evaluar las propuestas de normas (Habermas, 1987, 10-11 y 15-16). El potencial legitimador del procedimiento legislativo no se basa en última instancia ni en su legalidad, como pensaba Max Weber, ni en su influencia simbólico-expresiva que produce una confianza general en el Sistema, como ha sostenido Niklas Luhmann (1983). Su potencial legitimador básico radica en el hecho de que este procedimiento, al menos en lo que concierne a las normas constitucionales, se corresponde con la práctica discursiva que el nivel postconvencional de la conciencia moral y jurídica en la sociedad moderna requiere para la evaluación de pretensiones de validez normativa problemáticas.

La argumentación de Habermas sigue la primera de las dos alternativas que he distinguido para la justificación del concepto normativo de legitimidad dentro del programa de reconstrucción racional: se centra en las normas constitucionales que regulan el procedimiento parlamentario legislativo.

La teoría de la ética discursiva incluye en la moral y en los discursos morales simplemente cuestiones de justicia, esto es, cuestiones deontológicas concernientes a la corrección de las acciones y de las normas; quedan fuera del ámbito de la moral y de los discursos morales, por un lado, los problemas teleológicos relativos a los fines comunes y, por otro, los problemas axiológicos concernientes a valores y concepciones sobre la vida buena. Sin embargo, el Derecho moderno es en gran medida una suerte de sistema o estructura teleológica. Recientes discusiones en teoría del Derecho y en sociología del Derecho han puesto a menudo de relieve lo que viene a ser una tendencia del Derecho hacia finalidades: el Derecho se usa cada vez más como un instrumento para la consecución de objetivos políticos. El Derecho no transforma simplemente las normas morales en normas socialmente obligatorias, es decir, no sólo ayuda a la moral a resolver su problema de imputación; además de utiliza también para la consecución de objetivos comunes. Los procedimientos para la redacción y promulgación de las normas jurídicas no pueden, incluso en el nivel de la reconstrucción racional, analizarse simplemente como institucionalizaciones de los discursos práctico-morales en el sentido de la ética discursiva: debe prestarse atención también a las dimensiones teleológica y axiológica de los procedimientos de creación de normas jurídicas.

En relación con el aspecto teleológico, puede señalarse que tales regulaciones procedimentales no implican un discurso práctico-moral 
de justificación de la misma manera que, obviamente lo hacen, las disposiciones constitucionales sobre el Parlamento, sus procedimientos y sobre los derechos políticos básicos. Podemos distinguir tres tipos ideales de procedimientos para la creación de normas jurídicas que no sólo son fácticamente aplicados en las democracias occidentales, sino que también están implicados por las regulaciones jurídicas:

-el procedimiento discursivo en el que se trata de llegar a decisiones a través de una argumentación racional pública de acuerdo con el modelo del discurso práctico;

-el procedimiento estratégico en el que las decisiones se basan en compromisos entre intereses particulares; $\mathrm{y}$

-el procedimiento instrumental en el que la toma de decisiones se basa en un modelo finalístico de medios/fines en el que los fines se derivan de las necesidades funcionales «objetivas» en el terreno social de la actividad en cuestión.

El procedimiento discursivo se corresponde con la imagen del procedimiento parlamentario legislativo que nos viene dado por las reglas constitucionales y los principios de las democracias occidentales. El procedimiento basado en grupos de intereses sigue arquetípicamente el modelo estratégico. El procedimiento instrumental, a su vez, puede considerarse el tipo ideal de toma de decisión dentro del aparato administrativo cuando no implica representación de intereses.

Podemos distinguir entre procedimientos estratégicos o instrumentales manifiestos y encubiertos. Los primeros se dan cuando las normas jurídicas que regulan el procedimiento implican ya procedimientos estratégicos o instrumentales, como es el caso, por ejemplo, de la legislación sobre la negociación colectiva o de las «leyes de delegación» que transfieren el poder de dictar normas al ejecutivo. Un análisis de la «realidad constitucional», a su vez, puede demostrar que el procedimiento estipulado como discursivo por las normas constitucionales es de hecho estratégico o instrumental; en tal caso podemos hablar de creación estratégica o instrumental encubierta de normas. Así, uno de los puntos principales del análisis del procedimiento legislativo de Luhmann (1983, 11 ss., y 174 ss.) es que el procedimiento que, de acuerdo con las normas constitucionales, tiene un carácter supuestamente discursivo sigue en realidad un modelo estratégico o instrumental.

En el nivel de la reconstrucción racional, sin embargo, lo que es esencial son los procedimientos manifiestamente estratégicos e instrumentales. ¿Pueden armonizarse estos procedimientos con 
las exigencias que el propio Habermas establece con respecto a la naturaleza del procedimiento de creación de normas en el Derecho moderno? La respuesta de Habermas a esta cuestión puede interpretarse como afirmativa. Desde la perspectiva de Habermas, puede extraerse una legitimación correspondiente al principio discursivo de justificación tanto para el procedimiento estratégico como para el instrumental.

De acuerdo con la teoría de la ética discursiva, el procedimiento discursivo requiere la posibilidad de un interés común: el discurso se usa para buscar una comprensión mutua que, a su vez, está ligada a la presuposición de un interés común. Si los intereses particulares de las partes excluyen la posibilidad de un interés común, sólo puede alcanzarse una decisión conjunta a través de compromisos entre intereses particulares. Aunque estos compromisos no se basen en la comprensión alcanzada a través del discurso, Habermas argumenta que pueden justificarse indirectamente.

Habermas distingue entre compromisos verdaderos o equitativos y pseudo-compromisos; la posibilidad de una justificación indirecta alcanza sólo a los primeros. Pueden distinguirse tres requisitos para que un compromiso sea verdadero. Primero, que los intereses que constituyen el núcleo de la torna de la decisión deben ser realmente intereses particulares de un tipo tal que excluyan la posibilidad de un interés común. Segundo, todas las partes, esto es, todos los afectados por la decisión, deben tener un derecho igual a tomar parte en la formación del compromiso. Tercero, debe haber un equilibrio de poder entre las partes. Los contenidos del compromiso no pueden decidirse a través del discurso pero sí el núcleo de la toma de la decisión basada sobre compromisos (en mi terminología, el procedimiento estratégico) así como las condiciones que garanticen su equidad. Aquí es donde reposa la posibilidad de una justificación indirecta de los compromisos (Habermas 1975, 111-112; Habermas, 1981a, 323-324; Habermas, 1983, 82-83). Así, al usar el concepto de compromiso verdadero o equitativo Habermas trata de indicar el lugar legítimo del procedimiento estratégico en la toma de decisiones políticas. El concepto de compromiso verdadero puede usarse para legitimar, por ejemplo, una forma estratégica o corporativista de dictar normas tal como el sistema de convenios colectivos en el Derecho del Trabajo.

La legitimación del procedimiento instrumental, a su vez, puede derivarse de la distinción que traza Habermas entre el Sistema y el mundo de la vida. Cuando el Derecho se usa como un instrumento para la organización y el gobierno de los subsistemas 
autonomizados, la administración pública y la economía, Habermas (1981b, 536) argumenta que aquél no está directamente afectado por la pretensión de validez normativa que habría de ser resuelta a través del discurso. El punto de vista de Habermas implica que lo más importante para las normas que regulan la administración pública y la economía sería su racionalidad instrumental (o para ser más exactos, funcional), su aptitud para cumplir funciones de gobierno dentro del Sistema. La toma de decisión instrumental es el procedimiento más apropiado para tales funciones, dado que no necesita basarse en un entendimiento mutuo discursivo queda fuera del mundo de la vida y no requiere compromisos entre, por ejemplo, intereses económicos particulares.

De este modo, puede presentarse la misma posibilidad de justificación indirecta tanto para el procedimiento instrumental como para el procedimiento estratégico: también a este respecto, la tarea que le queda al procedimiento discursivo es especificar el núcleo de la toma de decisiones. De esta forma, en opinión de Habermas, podemos demostrar que también la toma de decisiones políticas instrumental o funcional tiene su lugar legítimo en el conjunto de procedimientos para dictar normas jurídicas.

Si mi interpretaciones correcta, el ámbito marcado por Habermas para el procedimiento discursivo de creación de normas está más o menos limitado: como una cuestión de hecho, en sentido cuantitativo, en la sociedad moderna del capitalismo tardío la mayoría de las regulaciones jurídicas permanecen fuera de él. El principio discursivo de justificación sólo cubre aquellos conjuntos de normas jurídicas que regulan las esferas de actividad situadas dentro del mundo de la vida o los contenidos de las que al menos tienen una conexión directa con las normas morales que guían la actividad comunicativa en el mundo de la vida; utilizando la terminología del propio Habermas, es una cuestión del Derecho como institución (Recht als Institution).

Por otro lado, Habermas utiliza la noción de Derecho como medio (Recht als Medium) para referirse a aquellas regulaciones jurídicas que organizan los subsistemas de la economía y del Estado o la administración pública. Según Habermas estos subsistemas están guiados por el dinero y el poder, y a través de estos medios han llegado a hacerse independientes del mundo de la vida. El Derecho como medio está representado por la mayor parte del Derecho económico y del administrativo (Habermas 1981b, 536-537).

Los criterios que Habermas utiliza en la justificación del ámbito legítimo de aplicación del procedimiento estratégico e instrumental 
pueden reconducirse a la distinción entre el Sistema y el mundo de la vida que él adopta en su análisis de la sociedad moderna. También los conceptos de Derecho-como-medio y de Derecho-como-institución están construidos con arreglo a esta distinción.

Las críticas que se han esgrimido contra esta distinción han mostrado que ni siquiera los sectores de la economía y de la administración pueden liberarse a sí mismos de los mecanismos sociales de integración que requieren actividad comunicativa. Estos mecanismos también pueden regularse y fomentarse a través del Derecho. Esto se demuestra, por ejemplo -se dice- por la regulación de la democracia industrial o el principio de equidad adoptado en el Derecho de contratos del Estado del bienestar. En efecto, los conceptos de Derecho como medio y de Derecho como institución ofrecen sólo dos perspectivas para el análisis del Derecho; no permiten agrupar de forma dicotómica a las normas jurídicas. Y cuando la dicotomía entre Derecho como medio y Derecho como institución se relativiza, cuestionamos al mismo tiempo la propuesta para la delimitación del ámbito legítimo de los diversos procedimientos para crear normas: ya no hay ninguna razón para situar a priori a las regulaciones económicas y administrativas fuera del procedimiento discursivo.

Las limitaciones a priori del procedimiento discursivo pueden criticarse también desde el punto de vista de la presuposición de un interés común. En la teoría de la ética discursiva, esta presuposición se introduce a través del principio de universalización ${ }^{3}$. Sin embargo, el papel de este principio y de la precondición del interés común es problemático tanto en la teoría de la ética discursiva como en la teoría de la legitimidad procedimental del Derecho. En la teoría de la ética discursiva uno puede argumentar de la siguiente forma: como el interés común mismo sólo puede determinarse a través del discurso, el principio de universalización no parece añadir nada al principio de la ética discursiva, esto es, a la demanda de que las cuestiones normativas controvertidas deberían resolverse en el discurso práctico (Cf. Benhabid, 1986, 303 ss.).

${ }^{3}$ En la teoría de la ética discursiva de Habermas, el principio de universalización tiene el status de una regla argumentativa necesaria para los discursos prácticos. Habermas $(1983,103)$ ha especificado este principio de la siguiente manera: Sólo aquellas normas pueden ser válidas, las que todos los concernidos -esto es, todos los afectados por la norma en cuestión- aceptan o pueden aceptar como participantes en un discurso práctico. 
En mi opinión, tampoco la posibilidad de un interés común puede ser considerada como una precondición a priori del procedimiento discursivo de creación de normas. Para establecer que las partes implicadas no participan de un interés común, también tenemos que recurrir al discurso. Así, es imposible distinguir nítidamente entre el procedimiento discursivo y el estratégico, y no hay tampoco ninguna razón para hacerlo. De alguna manera, esto está también implicado por los prerrequisitos procedimentales de los compromisos equitativos formulados por Habermas, que son muy similares a los principios de libertad e igualdad sobre los que un discurso debería basarse: entre las condiciones de los compromisos equitativos se incluye que todas las partes implicadas tengan el derecho a participar y que haya un equilibrio de poder entre ellas. Aun cuando el objetivo del discurso sea llegar a un consenso, puede resultar imposible alcanzarlo. ¡Por qué no podría un discurso tener también como resultado un compromiso equitativo!

El separar estrictamente las cuestiones deontológicas de justicia de los otros aspectos de las cuestiones prácticas puede criticarse también desde el punto de vista axiológico; y esto vale también para el concepto normativo de legitimidad desarrollado sobre la base de la ética discursiva. El aspecto axiológico revela un problema en el concepto de legitimidad de Habermas que yo llamaría el problema del condicionamiento cultural. Este problema nos resulta ya familiar como consecuencia de las acusaciones de etnocentrismo que se han dirigido contra el concepto de racionalidad comunicativa o discursiva de Habermas. No obstante, el problema del etnocentrismo no nos fuerza a abandonar la racionalidad discursiva como base normativa de la teoría de la sociedad occidental moderna y de su Derecho cuyas nociones de racionalidad lo satisfacen.

Pero incluso esta solución no nos libra completamente del problema del condicionamiento cultural. En la sociedad moderna este problema está conectado con la diferenciación de concepciones sustantivas del Derecho, es decir, con la diferenciación de culturas jurídicas: el análisis de las concepciones de Derecho en la sociedad moderna no puede, incluso en un examen de legitimidad, limitarse a las estructuras generales de la conciencia moral y jurídica postoconvencional. Habermas enfatiza que hay una exigencia directa de justificar el contenido de aquellos conjuntos de normas jurídicas que caen dentro de su noción de Derecho-como-institución. Sin embargo, es evidente que esta exigencia recibe diferentes respuestas en las diferentes culturas jurídicas. Esta observación está en el fondo por ejemplo del concepto 
de auditorio particular ideal de Aulis Aarnio (1987, 225).

En conexión con el concepto de auditorio particular ideal, Aarnio resalta la naturaleza dependiente de valores del Derecho y de su justificabilidad, así como los vínculos entre los valores y el pluralismo de las formas de vida. Tanto Aarnio como Habermas excluyen del ámbito de las cuestiones discursivamente solubles aquellas diferencias de valores que son una manifestación de la pluralidad de formas concretas de vida. Pero esto no afecta al análisis del Derecho de Habermas: según éste, los problemas normativos de la moral y del Derecho no tienen que ver con los valores, con la «vida ética» (Sittlichkeit), sino que son cuestiones de justicia que de alguna manera atraviesan los diferentes sistemas de valores (Habermas, 1983, 118-119 y 189-190).

Sin embargo, resulta problemático trazar una distinción nítida entre valores y normas, entre concepciones de la «vida ética» y moral. Podemos seguir, por ejemplo, a John Rawls $(1980,5)$ que distingue entre el concepto de justicia y las concepciones de la justicia, y argumenta que sólo los valores dan contenido a estas últimas; en otras palabras, que las concepciones de la justicia están unidas a concretas formas de vida y también a actores colectivos. Si esto se acepta, entonces también el concepto de legitimidad normativa del Derecho debe corregirse en la dirección indicada por la noción de auditorio particular ideal de Aarnio.

Las observaciones críticas sobre los diferentes procedimientos para la creación de normas y el aspecto axiológico de la aceptabilidad de las normas jurídicas parecen conducir a la siguiente conclusión. En la reconstrucción racional de los procedimientos para la creación de normas jurídicas y en el desarrollo de un concepto normativo de la legitimidad del Derecho moderno, no es suficiente con recurrir sólo al modelo de los discursos práctico-morales de justificación de normas. El concepto de legitimidad discursivo-procedimental parece requerir, en lugar de la teoría de la ética discursiva, una teoría general del discurso práctico o, más generalmente, de la formación racional de la voluntad colectiva. Tal teoría debería también tomar en cuenta los aspectos teleológico y estratégico de las cuestiones prácticas.

${ }^{4}$ Véase un reciente artículo de Habermas publicado en Ratio Juris, vol. 2, 1989. En este artículo Habermas parece admitir la necesidad de una teoría más amplia del discurso práctico o de la formación racional de la voluntad colectiva para el análisis de los procedimientos de creación del Derecho. Lo que en mi opinión es todavía problemático es su insistencia en la separación estricta de los aspectos ontológico. axiológico y teleológico de las cuestiones prácticas y de los correspondientes tipos de discurso práctico. 
Si dentro del armazón de la pragmática universal es posible desarrollar tal teoría general (reconstructiva), donde los discursos práctico-morales figuren simplemente como un tipo o como un aspecto de los discursos prácticos, es una cuestión que no puede tratarse aquí.

Dentro de los procedimientos estratégicos e instrumentales de creación de normas he distinguido entre procedimientos manifiestos encubiertos. Un procedimiento que, en el nivel de las normas procedimentales, se supone que es de naturaleza discursiva, puede en realidad seguir más bien el modelo estratégico o el instrumental. A la luz de esta distinción, es importante especificar el status de los resultados conseguidos con el programa de reconstrucción racional. Lo que la reconstrucción racional puede suministrar es un concepto normativo de legitimidad, de forma tal que partiendo de la materia misma se derive de alguna manera un patrón crítico: es decir, partiendo del Derecho moderno y de sus procedimientos. Pero la reconstrucción racional en sí misma no llega a suministrar respuestas a cuestiones sobre la realidad social; no debería entenderse como una descripción de la realidad social.

Es tarea de la investigación sociológica examinar si los procedimientos reales de creación de normas jurídicas corresponden a las implicaciones de las normas procedimentales. El concepto normativo de legitimidad plantea, por ejemplo, los siguientes problemas sociológicos: ¿Corresponde el proceso real de creación de normas a las condiciones de los discursos ideales? ¿En qué aspectos se desvían los procedimientos reales del procedimiento ideal? ¿Por qué tipo de mecanismos se producen estas desviaciones? Puede ser importante insistir en que estas cuestiones no presuponen necesariamente una teoría sociológica particular. Así, es concebible que los procesos reales se enfoquen, por ejemplo, como sistemas sociales en la forma propuesta por Luhmann o como campos sociales en el marco de la teoría sociológica de Pierre Bourdieu. En investigaciones sociológicas empíricas informadas por los resultados de la reconstrucción racional, los conceptos normativo y empírico de legitimidad se enfrentan de alguna manera uno a otro.

El estatus de los resultados de la reconstrucción racional debe evaluarse también con respecto a las propuestas de reforma al nivel institucional y organizativo. Habermas ha enfatizado fuertemente la distinción entre el principio discursivo de legitimidad y las conclusiones organizativas e institucionales inspiradas en él. Por ejemplo, ha criticado a Rousseau por haber confundido, en la teoría del contrato social y de la soberanía, el principio 
procedimental de justificación con la forma de su institucionalización. El concepto de voluntad general, "volonté générale», en la teoría de Rousseau no sólo expresa la base válida de la soberanía política legítima. También define su sujeto institucional. Habermas (1976, 279), sin embargo, argumenta que la cuestión de la legitimidad o de la validez debe distinguirse de la cuestión de la institucionalización u organización, cuya solución está siempre ligada a situaciones históricamente cambiantes y concretas.

Es evidente que sobre la base de la reconstrucción racional, no está justificado hacer propuestas de reforma institucional muy precisas y detalladas. A pesar de esto, la distinción de Habermas entre el patrón ideal, normativo, y su forma de institucionalización me parece demasiado estricta. Al menos algunos tipos de directrices institucionales generales pueden desarrollarse y justificarse en el propio nivel de la reconstrucción racional. Así, la modificación del concepto normativo de legitimidad en la dirección indicada por el concepto de auditorio particular ideal de Aarnio remite a la descentralización de la creación de normas jurídicas que ha sido propuesta en recientes debates como una forma de fortalecer las legitimidad democrática del sistema jurídico. Ingeborg Maus (1986, 322-323), por ejemplo, ha propuesto que las funciones de la democracia del Estado centralizado en la creación del Derecho se limiten a aquellas cuestiones que realmente afecten a todos los miembros de la sociedad. Las regulaciones sobre materias sustantiva y personalmente limitadas deberían delegarse a las partes afectadas, es decir, deberían ser asunto de procesos sociales democráticamente organizados de formación de normas. El propio análisis de Habermas (1985, 417-418) de la pluralización del mundo de la vida racionalizado y de las posibilidades de esferas públicas parciales autónomas parecen suministrar un apoyo adicional (sociológico) a tales propuestas para la descentralización del procedimiento discursivo de creación del Derecho.

\section{La aplicación del Derecho}

Habermas ha resaltado que el Derecho moderno no puede obtener su legitimidad solamente a partir del discurso práctico que ha sido institucionalizado en el procedimiento legislativo. En su opinión, especialmente en la etapa del Estado Social del bienestar de las sociedades modernas, las leyes no pueden redactarse 
de la forma semánticamente inequívoca que se requiere para su aplicación lógica subsuntiva: el juez no puede ser el «autómata de la subsunción» descrito por Weber. La aplicación de las normas jurídicas requiere inevitablemente un ulterior desarrollo constructivo del Derecho. Pero, Habermas (1987, 10-11 y 15) ha argumentado que también el procedimiento judicial puede entenderse como un discurso práctico institucionalizado.

El propio Habermas no ha procedido a un análisis muy minucioso de la discursividad que garantizaría la legitimidad de la aplicación del Derecho. Por ejemplo, él no ha introducido su distinción entre Derecho como medio y Derecho como institución al referirse a la aplicación del Derecho. No sabemos si se inclina por extender su tesis también a la aplicación del Derecho que abarca los conjuntos de normas que él considera como medios. También permanece poco claro qué posible efecto pueda tener seguir diferentes procedimientos en la creación de normas jurídicas: si, por ejemplo, en un cierto campo de regulación, está legitimado seguir el procedimiento estratégico, ¿la justificabilidad de la desviación del modelo discursivo se extiende también a la aplicación del Derecho? Por ejemplo, en Finlandia los mismos factores que han llevado al procedimiento estratégico en la creación de normas jurídicas han tenido influencia también sobre la organización de la aplicación del Derecho, como se muestra por ejemplo por la consideración basada en representación de intereses de los conflictos acerca de convenios colectivos ante un tribunal laboral.

La «Theorie der juristischen Argumentation», de Alexy (1983) ofrece un ejemplo representativo de los argumentos que se han presentado en favor de la naturaleza discursiva de la aplicación del Derecho. Su tesis básica es que las argumentaciones jurídicas, por ejemplo, los procedimientos judiciales, son casos especiales del discurso práctico. Son discursos prácticos, en primer lugar, porque tratan de cuestiones práctico-normativas y, en segundo lugar, porque su resultado (por ejemplo, una decisión judicial) implica la pretensión de validez normativa. Estos casos especiales difieren de lo que Alexy llama «discurso práctico general», en que se desarrollan bajo ciertas condiciones restrictivas. La más crucial de estas restricciones es que están limitados por el Derecho vigente. También resultan restricciones del hecho de que el proceso de argumentación está sometido a límites fijos de tiempo y está regulado por disposiciones procedimentales fijas. Además, las partes buscan más una decisión que les sea favorable que una que sea normativamente correcta, y esta meta guía, asimismo, su comportamiento en el proceso. Por otra parte, la 
posición del juez y la del acusado en asuntos penales son manifestaciones de un reparto de roles desigual; la participación del acusado no es voluntaria; y el acusado no tiene obligación de decir la verdad.

Para Alexy, estas desviaciones del modelo ideal de discurso, de la situación ideal de diálogo, no nos impiden describir el proceso de aplicación del Derecho como un discurso práctico. En su opinión, lo esencial es que el resultado del proceso, la decisión del tribunal, implica la pretensión de validez normativa, y que al margen de los motivos subjetivos de las partes y de sus abogados, también las partes formulan esta pretensión en sus argumentos, es decir, presuponen que sus argumentos podrían ser aceptados bajo las condiciones de una situación ideal de diálogo (Alexy, 1983, 261-273).

El problema fundamental que presenta la argumentación de Alexy en relación con su propia tesis es el siguiente. Parece que él usa la pretensión de validez normativa planteada por los enunciados normativos como base para la extracción de conclusiones en lo relativo a la producción de estos enunciados: ya que el resultado del proceso implica la pretensión de validez normativa, debería ser posible describir este proceso en términos del discurso práctico. Sin embargo, esto no es necesariamente así: una pretensión de validez que sólo puede encontrarse a través del discurso no dice en sí misma nada sobre el proceso a través del cual la norma o enunciado normativo en cuestión se generó. Las normas y los enunciados normativos que plantean la pretensión de validez para que sea tomada en consideración en el discurso pueden producirse también por medios distintos al del discurso.

Una vez que rompemos la cadena del razonamiento que lleva desde la pretensión de validez que está implicada en las decisiones de los tribunales al proceso a través del cual estas decisiones se producen, las desviaciones de las reglas del discurso asumen un significado diferente del que Alexy les quiere dar. Las desviaciones están relacionadas, por un lado, con los argumentos que se tienen en cuenta en el proceso y, por otro lado, con el procedimiento mismo y sus roles. Las restricciones en relación con los argumentos admisibles -la limitación al Derecho vigente- no trastocan ellas mismas la tesis de Alexy mientras podamos asumir que el propio Derecho vigente es válido en el sentido de la teoría discursiva. Lo decisivo son las desviaciones relativas al procedimiento y sus roles. Ya que las reglas discursivas de simetría, ausencia de coacción y sinceridad no rigen estrictamente y dado que las partes en el proceso no se supone que tengan 
como único motivo permitido buscar el resultado normativamente correcto, es difícil estar de acuerdo con la tesis del caso-especial de Alexy. Para que fuera posible entender el proceso de la aplicación del Derecho como un discurso práctico, este proceso debería corresponder más bien a un procedimiento de acuerdo extra-judicial en el que las partes mismas (esto es, sin intervención de no-partes, tales como el juez) intentaran resolver sus conflictos de acción surgidos en su práctica comunicativa cotidiana.

Así, incluso en el nivel de la reconstrucción racional, no es probablemente posible describir el procedimiento judicial como un discurso práctico en el que los participantes serían las concretas partes y en el que la meta sería su entendimiento mutuo racionalmente motivado. Sin embargo, el universo limitado de las partes concretas no es el único punto de partida concebible en la evaluación de la naturaleza discursiva de la adjudicación. Podemos distinguir al menos tres círculos concéntricos desde cuya perspectiva podemos aproximarnos al problema de la naturaleza discursiva de la aplicación del Derecho:

-las partes concretas,

-la comunidad jurídica en sentido estricto compuesta por los juristas prácticos $\mathrm{y}$, en general, los expertos en Derecho

-La comunidad jurídica en sentido amplio que abarca a toda la sociedad.

Desde la perspectiva de la comunidad jurídica, los argumentos presentados y las decisiones tomadas en casos individuales llegan a formar parte del continuum de la discusión jurídica o social general sobre los contenidos del ordenamiento jurídico; aparte de los procedimientos judiciales, otra forma institucional de la discusión que transcurre dentro de la cultura de los expertos en Derecho es la dogmática jurídica. Desde el punto de vista de la comunidad jurídica en sentido estricto, las decisiones de los tribunales y la interpretación y las recomendaciones normativas de la dogmática jurídica son enunciados normativos análogos unos a otros. La validez de estos enunciados es evaluada en el continuum discurso jurídico, en el flujo de las decisiones razonadas de los tribunales y de las investigaciones de la dogmática jurídica. Este punto de vista es conocido desde la reciente discusión en teoría jurídica sobre la racionalidad de la dogmática jurídica: la interpretación en la dogmática jurídica se ha analizado como un diálogo en el que los enunciados normativos van 
siempre dirigidos a su aceptación por un auditorio específico.

En lo que se refiere a la conexión de la naturaleza discursiva de la aplicación del Derecho y, al mismo tiempo, la validez normativa de sus resultados, por un lado, con la comunidad jurídica en sentido estricto, por otro, el principal problema concierne a los participantes en la discusión. El concepto de comunidad jurídica en sentido estricto limita el derecho de participación de una forma no armónica con el modelo ideal del discurso práctico. Sólo los expertos en Derecho pueden tomar parte en la discusión, en lugar de todos los que están afectados por la norma o por los puntos de vista interpretativos. En el mejor de los casos, la discusión entre expertos sólo puede ser un discurso advocatorio que se lleva a cabo en nombre de las partes reales, esto es, en nombre de la comunidad jurídica en sentido amplio.

Entonces, ¿qué cabe decir respecto de la comunidad jurídica en sentido amplio? ¿Podemos considerar la aplicación del Derecho como una parte de una discusión pública en la que también el público en general participa y en la que se evalúan las pretensiones de validez de las decisiones y argumentos jurídicos? Tal interpretación encuentra un obstáculo crucial relacionado con una de las observaciones que tanto Weber como Habermas hacen en el diagnóstico de la sociedad moderna, a saber, la diferenciación de las culturas y discursos de los expertos en relación con el mundo de la vida cotidiana de la sociedad. La comunidad jurídica en sentido estricto emplea en la argumentación jurídica su propio lenguaje especial con el que tiende a situar la discusión fuera del alcance de la comunidad jurídica en sentido amplio. Para que sea posible superar la división entre la comunidad jurídica en sentido estricto $\mathrm{y}$ en sentido amplio, la argumentación jurídica debería aproximarse más a la argumentación práctica general. Sin embargo, si la división se borra completamente, se corre el riesgo de perder los beneficios que obviamente suministra una cultura de expertos en Derecho diferenciada. Alexy (1983, 326-332) ha analizado estos beneficios como funciones de la dogmatización del Derecho. Así, por ejemplo, a través de sus funciones de estabilización y control la dogmatización del Derecho promueve la uniformidad de la aplicación del Derecho, la realización del requisito de la justicia formal.

Desde el punto de vista de la comunidad jurídica en sentido amplio, la cultura institucionalizada de los expertos, representada por los que participan en la toma de decisiones jurídicas y por los juristas teóricos, puede entenderse como una restricción sobre el discurso práctico que se introduce a la hora de tratar con normas jurídicas y con propuestas interpretativas. Sin embargo, 
los argumentos que Alexy presenta para defender las funciones de la dogmatización del Derecho implican que esta restricción puede ser justificable también desde el punto de vista de la comunidad jurídica en sentido amplio: la comunidad jurídica en sentido amplio puede, a través del discurso, llegar a aceptar tales desviaciones del modelo ideal del discurso práctico. De manera análoga, uno tal vez podría justificar también aquellas desviaciones del procedimiento judicial respecto del modelo ideal de discurso que vimos cuando nos aproximábamos a la cuestión desde la perspectiva de las partes concretas: puede ser que las excepciones que se hacen a las reglas del discurso puedan justificarse a través del discurso en una comunidad que comprenda también a las concretas partes potenciales en futuros procesos (Cf. Alexy, 1983, 37).

Si el procedimiento para la aplicación del Derecho ha de ser analizado en términos de discurso práctico, esto parece requerir recurrir al concepto de discurso advocatorio o simulado. El discurso jurídico en la comunidad jurídica en sentido estricto puede tal vez considerarse como un discurso advocatorio que es llevado a cabo en nombre de las partes reales. Y la toma de decisiones en tribunales en los que las partes no tienen derecho a participar puede tal vez describirse como un discurso práctico simulado en el que el juez se supone que procede en su argumentación como si fuera un discurso real entre partes reales. Entonces el soporte específico que la teoría discursiva podría prestar a tales discursos simulados o advocatorios sería una suerte de principio regulativo que habría de ser seguido por los jueces y juristas teóricos en su argumentación. Argumentos en favor de esto pueden encontrarse en la teoría de la dogmática jurídica de Aarnio, aunque sus raíces provienen bastante más de la concepción de auditorio universal de Perelman que de la teoría de la ética discursiva. Aarnio $(1987,227)$ ha formulado el siguiente principio regulativo para la dogmática jurídica: la dogmática jurídica debería buscar resultados -propuestas de normas e interpretaciones- que probablemente recibirían el apoyo de la mayoría dentro de una comunidad jurídica que razonara racionalmente. Un principio regulativo similar podría formularse también para el poder judicial.

En el contexto de la aplicación del Derecho, la separación estricta entre cuestiones deontológicas de justicia y cuestiones teleológicas y axiológicas puede también criticarse con argumentos similares a los utilizados en el contexto de los procedimientos de creación de normas jurídicas. En la evolución del Derecho hacia una orientación finalística, las consideraciones teleológicas 
y axiológicas han adquirido un papel cada vez más importante en la argumentación de los tribunales. Buena muestra de ello es, por ejemplo, la discusión iniciada por Ronald Dworkin (1978) sobre el papel que los principios de base moral, por un lado, y las directrices políticas [policies], por otro, tienen en la toma de decisiones jurídicas. Así, puede argumentarse que las pretensiones de corrección dentro de los límites del Derecho vigente que suponen las decisiones de los tribunales no pueden reducirse meramente a una corrección moral definida en términos estrictos. Y, análogamente, también la reconstrucción racional del procedimiento de aplicación del Derecho -así como la reconstrucción racional de la dogmática jurídica- parece requerir como soporte una teoría general del discurso práctico o de la formación racional de la voluntad colectiva, y no simplemente una teoría del discurso práctico-moral tal como la teoría de la ética discursiva ha suministrado.

Como comentario final, puede ser útil repetir la observación a propósito de la relación entre la reconstrucción racional y la investigación sociológica. En el análisis de Luhmann (1983, 82 ss.) sobre el principio de publicidad en el procedimiento judicial, por ejemplo, el público en general es descrito como un auditorio observador, que es objeto de influencia simbólica y expresiva. Cuanto más próximo a la realidad esté este análisis, más alejados estaremos del ideal de una aplicación discursiva del Derecho, de la situación en la que también la aplicación del Derecho sería una parte de un continuum de discusión práctico-normativa que abarque a toda la sociedad.

El principio de legitimidad formulado en términos de una teoría reconstructiva del discurso no debería entenderse como una descripción de las prácticas de adjudicación presentes. De lo contrario, se corre el riesgo de que este principio se transforme en una ideología de legitimación. Para evitar este peligro, tenemos que subrayar el carácter crítico-normativo del principio de legitimidad frente a su uso descriptivo.

\section{Epílogo: Las dimensiones de la racionalidad del Derecho}

La cuestión de la legitimidad puede, al menos desde el punto de vista de la teoría discursiva, caracterizarse como una dimensión de la racionalidad del Derecho moderno.

La racionalidad del Derecho puede examinarse al menos en tres dimensiones diferentes. Podemos usar estas dimensiones, por ejemplo, para dar cuenta de la discusión actual sobre la supuesta 
crisis del Derecho moderno. Desde la primera dimensión, podemos discutir problemas de la sistemática interna del ordenamiento jurídico, las tendencias de la crisis en la racionalidad interna del Derecho. Desde la segunda dimensión, nuestra atención se centra sobre las relaciones entre el Derecho y su objeto de regulación, la racionalidad del objeto del Derecho. Y desde la tercera dimensión, la cuestión son los problemas de legitimidad del Derecho: si esta legitimidad tiene que ver con la aceptación real de normas jurídicas o con su aceptabilidad. Cuando el concepto de legitimidad es entendido en el último sentido, podemos hablar de la tercera dimensión de la racionalidad del Derecho, la racionalidad normativa del Derecho.

Especialmente en sociología del Derecho, la racionalidad del Derecho moderno es usualmente abordada desde el punto de vista de la teoría de Weber sobre el carácter racional-formal del Derecho moderno: la caracterización de Weber de la racionalidad formal del Derecho moderno y el proceso de materialización en que parecía basarse en el nivel de la acción sobre el concepto de racionalidad con arreglo a fines. El concepto de Habermas de racionalidad comunicativa o discursiva abre una manera alternativa de analizar los problemas del Derecho moderno. La teoría de la legitimidad procedimental del Derecho puede ser considerada como una aplicación de este concepto a la dimensión de la racionalidad del objeto del Derecho. Y, uno puede añadir, también los problemas de la racionalidad interna del Derecho moderno pueden ser analizados sobre la base del concepto de racionalidad discursiva. En qué forma y con qué resultados es una cuestión que debe, sin embargo, discutirse en otro lugar.

(Trad. de Josep Aguiló Regla) 


\section{REFERENCIAS BIBLIOGRÁFICAS}

Aarnio, Aulis, 1987, The Rational as Reasonable, Dordrecht: D. Reidel.

Alexy, Robert, 1978, Theorie der juristischen Argumentation, Frankfurt am Main: Surkamp.

Benhabid, Seyla, 1986, Critique, Norm, and Utopia, New York: Columbia University.

Habermas, Jürgen, 1975, Legitimation Crisis, Boston: Beacon.

—, 1976, Zur Rekonstruktion des Historischen Materialismus, Frankfurt am Main: Surkamp.

—, 1981a, «Die Utopie des guten Herrschers», en Kleine politische Schriften I-IV. 318-327. Frankfurt am Main: Surkamp.

—, 1981b, Theorie des Kommunikativen Handelns, vol. 1, Frankfurt am Main: Surkamp.

- 1983, Moralbewusstsein und kommunikatives Handeln, Frankfurt am Main: Surkamp.

—, 1985, Der philosophische Diskurs der Moderne, Frankfurt am Main: Surkamp.

—, 1987, «Wie ist Legitimität durch Legalität möglich?», en Kritische Justiz, 1: 1-16.

Luhmann, Niklas, 1983, Legitimation durch Verfahren, Frankfort am Main: Surkamp.

Maus, Ingeborg, 1986, «Verrechtlichung, Entrechtlichung und der Funktionswandel der Institutionen», en Rechtstheorie und politische Theorie im Industriekapitalismus, 277-331, München: Wilhelm Fink.

Rawls, John, 1980, A Theory of Justice, Oxford: Oxford University. 